\title{
Involvement of Developing Sympathetic Nervous System in Thyroxine-Mediated Submandibular Gland Nerve Growth Factor and Epidermal Growth Factor Responses
}

\author{
J. LAKSHMANAN, J. PADBURY, T. MACASO, D. WANG, U. BERI, AND D. A. FISHER
}

Department of Pediatrics, Harbor-UCLA Medical Center, UCLA School of Medicine, Torrance, California 90509

\begin{abstract}
Thyroxine (T4) administration in mice during the 2 nd wk of postnatal life elicits a precocious increase in submandibular gland-nerve growth factor (SMG-NGF) and epidermal growth factor (SMG-EGF) levels, but the mechanism(s) of T4 action has not been studied. The present report examines the role of the developing sympathetic nervous system (SNS) in the SMG-NGF and EGF responses to $\mathrm{T} 4$. For this purpose newborn mice were injected with $\mathrm{T} 4$ and/or 6-hydroxydopamine, a toxic congener of norephinephrine which causes selective destruction of sympathetic nerve terminals. The effectiveness of chemical sympathectomy was assessed by SMG-norepinephrine measurements using a sensitive radioenzymatic assay. The glandular norepinephrine contents were greatly reduced indicating that the dose and duration of 6-OHDA treatment were sufficient to cause a total sympathectomy in SMG tissue. In addition, the 6-OHDA treatment greatly reduced the wet weight and total protein content of the sympathetic superior cervical ganglia which innervate SMG tissue. SMG-NGF and EGF concentrations were measured by specific radioimmunoassays. 6-OHDA treatment alone did not affect the basal SMG-NGF and EGF concentrations. However, the maximal responses of SMGNGF and EGF to T4 administration were greatly reduced by concurrent treatment with 6-OHDA. In summary, the data demonstrate a critical role for developing sympathetic nervous system in the T4-stimulated increase in SMGNGF and EGF concentrations. (Pediatr Res 20: 232-236, 1986)
\end{abstract}

\section{Abbreviations}

T4, thyroxine

SMG, submandibular gland

NGF, nerve growth factor

EGF, epidermal growth factor

SNS, sympathetic nervous system

SCG, superior cervical ganglia

NE, norepinephrine

RIA, radioimmunoassay

Adult mouse SMG contains high concentrations of both NGF and $\operatorname{EGF}(1,2)$. NGF is a protein that plays a key role in the growth and maintenance of sympathetic and sensory neurons of

Received July 9, 1985; accepted October 31. 1985.

Address for correspondence Dr. J. Lakshmanan, Center for Neurologic Study,

11211 Sorrento Valley Road, Suite H, San Diego, CA 92121.

Supported by NIH Grants NS-17431A (J.L.) and HD-04270 (D.A.F.). the autonomic nervous system (3). EGF is a polypeptide which exhibits a potent mitogenic effect on a wide variety of cell types (4). NGF and EGF are synthesized and stored in the CGT of the SMG $(5,6)$. SMG-NGF and EGF levels are low during the first three weeks of life in the mouse (7), a time when the SMG are grossly immature. Both SMG-NGF and EGF levels undergo exponential increases after weaning (i.e. 21 days) when the SMG exhibits rapid and maximal cytodifferentiation. In sexually mature animals the SMG exhibits sexual dimorphism with respect to structure (8) and growth factor content, including both NGF and EGF $(9,10)$. The factor(s) and the mechanism(s) that regulate these developmental changes are not fully understood.

Several hormones are known to influence growth and maturation of mouse SMG $(11,12)$, including thyroxine, testosterone, and corticosterone, and these hormones have been recognized to augment the glandular contents of both NGF and EGF in adult animals $(10,13,14)$. However, the critical time period for the actions of these hormones on SMG-NGF and EGF and their participation in the normal ontogenesis of SMG-NGF and EGF are not clearly understood. Moreover, little information is available regarding the role of the autonomic nervous system in the growth and maturation of developing SMG $(15,16)$. Recent studies in our laboratory have indicated that both SMG-NGF (17) and EGF (18) are T4 responsive during the second week of life. In view of the fact that T4 in newborn animals has profound effects on the developing nervous system $(19,20)$, we examined the role of the SNS in mediating the T4 effect on developing SMG. The time of appearance of SMG-NGF and EGF response to $\mathrm{T} 4$ was studied in neonatal mice on day 16 following $\mathrm{T} 4$ and/ or 6-OHDA (a toxic congener of norepinephrine) administration from days 7-15. The data support a role for the developing SNS in mediating SMG-NGF and EGF responsiveness to T4.

\section{MATERIALS AND METHODS}

Animals. Time-dated, multiparous, pregnant Swiss-Webster mice were obtained from Simonsen Laboratories (Gilroy, CA). The mice were housed in the Harbor UCLA vivarium and given water and pelleted standard mouse chow ad libitum. Pups born within $16 \mathrm{~h}$ of each other were pooled and randomly distributed, eight pups per dam. The day of birth was counted as day zero. Four pups in each litter were marked by bobbing the tails. Each litter was housed with its mother in a plastic cage with wood shavings for bedding. Cotton was added to all cages for warmth. Cages were changed daily and clean shavings replaced.

Four pups in each litter were treated as controls, while the remaining four (bobbed tails) served as experimental animals. Control pups were injected subcutaneously either with $2 \mu \mathrm{l}$ of alkaline saline $(0.9 \% \mathrm{NaCl}$ in $0.001 \mathrm{~N} \mathrm{NaOH})$ or ascorbic acid in saline $(0.5 \mathrm{mg} / \mathrm{ml})$. Experimental pups were injected with T4 
$(0.4 \mu \mathrm{g} / \mathrm{g}$ body weight/day) in a $2 \mu \mathrm{l}$ volume of alkaline saline and/or $2 \mu \mathrm{l}$ of 6-OHDA (100 $\mu \mathrm{g} / \mathrm{g}$ body weight/day) in ascorbic acid-saline solution. All injections were given from day 7 to 15 . A total of 64 pups was used for each group. Animals were sacrificed on day 16 and each animal was weighed prior to sacrifice. Blood was collected from the inferior vena cava for determination of serum hormone concentrations. The SMG were removed, trimmed of connective tissue, weighed, and frozen immediately on dry ice for later measurements of NGF and EGF content. For glandular NE estimation individual glands were homogenized immediately in a Teflon-glass homogenizer at 0 $4^{\circ} \mathrm{C}$ in $1 \mathrm{ml}$ volume of $0.1 \mathrm{~N}$ perchloric acid, containing $5 \mathrm{mM}$ reduced glutathione. They were centrifuged at $15,000 \times g$ for 30 $\min$ at $4^{\circ} \mathrm{C}$. The supernatants were used for norepinephrine determination by a radioenzymatic assay (21).

For DNA determinations, pooled SMG tissues (four per tube) were homogenized in nine volumes of ice-cold distilled water and the homogenate was precipitated by adding perchloric acid to a final concentration of $10 \%$. The precipitate was processed for DNA determination as previously described (17).

$N G F$ and EGF RIA. SMG tissues were pooled to obtain sufficient material for measurement, usually four glands for control groups and two to three glands for animals treated with T4 and 6-OHDA. SMG tissues removed from animals receiving $\mathrm{T} 4$ injection alone were processed individually. As indicated, all glands were frozen on dry ice immediately after removal and stored at $-70^{\circ} \mathrm{C}$ until further analysis. The tissues were homogenized in 10 volumes of $0.05 \mathrm{M}$ phosphate buffered saline, $\mathrm{pH}$ 7.2; the homogenates were centrifuged at $145,000 \times g$ for $1 \mathrm{~h}$ and the supernatants used for NGF and EGF determinations.

NGF RIA was performed using an NGF antiserum containing at least two populations of high affinity antibodies with a mean affinity constant of $5.8 \times 10^{-10} \mathrm{liter} / \mathrm{mol}$. The antiserum was used at a final dilution of $1: 320,000$. No cross reaction was observed with the $\alpha$ or $\gamma$ subunits of 7S NGF, renin, EGF or insulin when tested at $1 \mu \mathrm{g} /$ tube. The $\beta \mathrm{NGF}$ subunit and the $7 \mathrm{~S}$ NGF react similarly with the antiserum. The RIA can detect $16-$ $20 \mathrm{pg} /$ tube. Nonspecific binding was never more than $6 \%$ of total binding. NGF used for immunization, iodination, and standard was purified from adult male mouse SMG by the method of Mobley et al. (22), as modified by Chapman et al. (23). Iodination was performed with chloramine $T$ (24) and labelled $\beta \mathrm{NGF}$ was purified on a $\mathrm{CM}$-cellulose column using buffer systems similar to those employed for the purification of $\beta$ NGF by Mobley et al. (22). The specific radioactivity of ${ }^{125} \mathrm{I}-$ NGF calculated using a self displacement assay ranged from $375-420 \mathrm{cpm} / \mathrm{pg}$. Buffer, incubation and separation were previously described (25).

The EGF-RIA was performed using an EGF antiserum containing two populations of high affinity antibodies with a mean affinity constant of $1 \times 10^{-10} \mathrm{liter} / \mathrm{mol}$. The antiserum was used at a final dilution of 1:250,000. No cross-reactivity was noted against renin, insulin, and myelin basic protein. Cross-reactivity with NGF was less than $0.01 \%$. The antiserum binds both standard low molecular weight EGF (6045d) and high molecular weight EGF $(74,000 \mathrm{~d})$. No cross-reaction was observed with purified EGF-binding protein $(29,300 \mathrm{~d})$. Non-specific binding was less than $4 \%$. EGF used for iodination and standard was purified from SMG of adult male mice treated with testosterone propionate (26). Iodination was performed using chloramine $T$ and ${ }^{125}$ I-EGF was purified on a Sephadex G-25 column, developed and equilibrated with $0.05 \mathrm{M}$ phosphate buffered saline. Specific radioactivity ranged from $600-800 \mathrm{cpm} / \mathrm{pg}$. The buffer, incubation, and separation have been described previously (27).

Serum hormone measurements. Serum T4 and T3 concentrations were measured using the methods of Chopra and coworkers $(28,29)$.

\section{STATISTICAL ANALYSIS}

Data are expressed as mean \pm SEM. Since preliminary results indicated no differences in the various parameters measured between groups of animals treated with alkaline saline and ascorbic acid solutions, the data from both groups of animals were pooled and treated as representative of controls. For multiple comparison, the differences between means were determined by one way analysis of variance, followed by Student's Newman Keuls test. Significance was assumed at the $5 \%$ level $(p<0.05)$.

\section{RESULTS}

Influence of T4 on somatic growth and serum hormones. The experimental design, body weights, SMG weights, and serumT4 and $\mathrm{T} 3$ concentrations are shown in Table 1. Group A (control) animals were treated with vehicle solutions from days 7 to 15 . Groups B, C, and D received T4, 6-OHDA and T4 + 6-OHDA injections, respectively. All animals were sacrificed on day 16. Both 6-OHDA (group C) and T4 + 6-OHDA (group D) treatments significantly affected body growth as indicated by the decrease in body weight compared to group A animals ( $p<$ 0.05 ). Mean nose to rump lengths were also significantly decreased in groups $\mathrm{C}$ and $\mathrm{D}(p<0.01)$.

Mean serum T4 levels were elevated in groups B $(p<0.01)$ and D $(p<0.01)$ compared to group A. Mean serum T3 levels also were significantly elevated relative to control levels in group $\mathrm{B}$ and $\mathrm{D}$ animals $(p<0.01)$. The mean T3 value was higher in group D than in group B animals $(p<0.05)$. SMG-wet weights (expressed as percent of body weight) were significantly increased in groups B, C, and D compared to control animals $(p<0.01)$.

Assessment of chemical sympathectomy. To assess the effectiveness of chemical sympathectomy, SMG-NE content was

Table 1. Effect of T4 and/or 6-OHDA in neonatal mice*

\begin{tabular}{lccccc}
\hline & & Body length & \multicolumn{2}{c}{ Serum Iodothyronines } & SMG-wt \\
\cline { 3 - 5 } Treatment group & Body wt $(\mathrm{g})$ & (nose to rump) & T4 $(\mu \mathrm{g} / \mathrm{dl})$ & $\mathrm{T} 3(\mathrm{ng} / \mathrm{dl})$ & $(\mathrm{g} / 100 \mathrm{~g}$ body wt) \\
\hline Vehicle group A & $8.08 \pm 0.17$ & $6.15 \pm 0.11$ & $7.9 \pm 0.4$ & $226 \pm 7.0$ & $0.68 \pm 0.16$ \\
T4 group B & $7.77 \pm 0.38$ & $6.28 \pm 0.11$ & $36.0 \pm 4.7 \dagger$ & $606 \pm 11.0 \dagger$ & $0.83 \pm 0.03 \dagger$ \\
6-OHDA group C & $6.53 \pm 0.17 \dagger$ & $5.62 \pm 0.08 \dagger$ & $7.3 \pm 0.6$ & $267 \pm 40$ & $0.88 \pm 0.03 \dagger$ \\
T4 + 6-OHDA group D & $5.7 \pm 0.30 \dagger$ & $5.62 \pm 0.10 \dagger$ & $44.8 \pm 5.6 \dagger$ & $752 \pm 56 \dagger$ & $0.99 \pm 0.03 \dagger$ \\
\hline
\end{tabular}

* Newborn mice were treated from days 7-15 with vehicle (alkaline saline or ascorbic acid solution) while their littermate pups were treated with T4 $(0.4 \mu \mathrm{g} / \mathrm{g}$ body weight/day) and/or 6-OHDA (100 $\mu \mathrm{g} / \mathrm{g}$ body weight/day). All pups were sacrificed on day 16 . Values represents mean \pm SEM. A total of 64 pups were used in each group. The results obtained in three experiments $(\mathrm{N} 1=16, \mathrm{~N} 2=16, \mathrm{~N} 3=32)$ were not different for any variables and were thus pooled. Pools of sera obtained from four pups were used for serum hormone measurements.

$\dagger$ Significantly $(p<0.01)$ different from group A. 

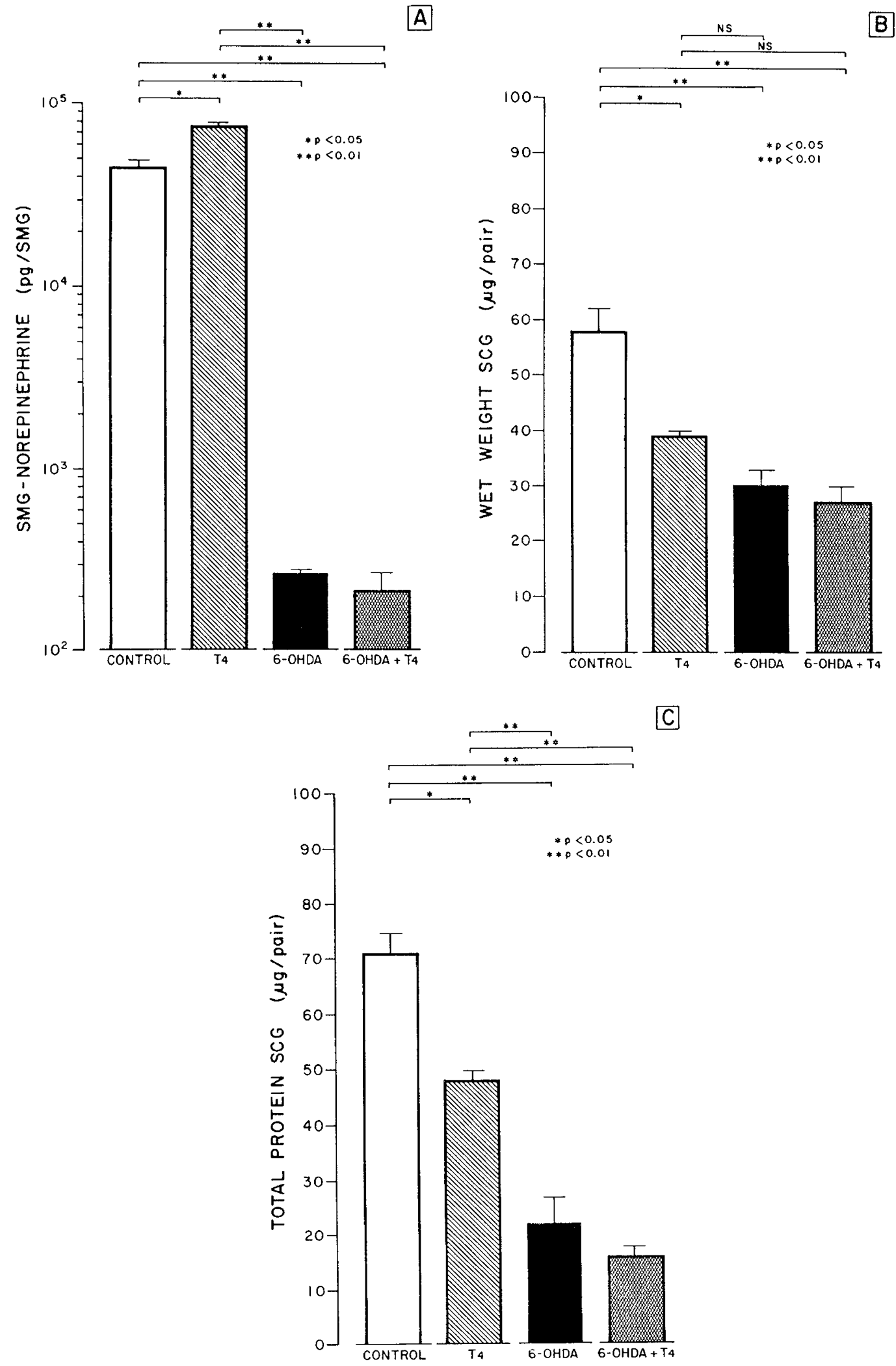

Fig. 1. Effect of neonatal T4 and/or 6-OHDA treatment on SMG-NE levels, wet weight, and protein content of sympathetic SCG. Newborn mice were treated with T4 and/or 6-OHDA from days 7-15 with doses as described in Table 1. All pups were sacrificed on day 16. $A$, SMG-NE content as determined by a radioenzymatic assay (21). $B$, SCG wet weight determined on a Cahn electrical balance. $C$, total SCG protein content as determined by the method of Peterson (40). The results obtained in three different experiments $(3 \times 6$ animals/group) were not significantly different and were thus pooled. Values represent mean \pm SEM.

measured by a radioenzymatic assay (21). SMG-NE values were reduced to less than $1 \%$ of control levels in animals treated with 6-OHDA and T4 +6-OHDA, indicating a total chemical sympathectomy (Fig. 1 $A$ ). The mean SMG-NE content increased in the T4-treated group compared to control animals $(p<0.05)$. Also, we examined the wet weight and total protein content of SCG, the principle sympthetic ganglia that innervate SMG tissue. Both the ganglia wet weights (Fig. $1 B$ ) and protein contents (Fig 
$1 C$ ) were signficantly reduced in groups $\mathrm{B}, \mathrm{C}$, and $\mathrm{D}$ (B versus $\mathrm{A}, p<0.05 ; \mathrm{C}$ and $\mathrm{D}$ versus $\mathrm{A}, p<0.01$ ).

Effects of T4 and/or 6-OHDA administration on SMG-NGF and EGF SMG-NGF and EGF contents were measured by respective RIA methods; the results are shown in Figure $2 A$ and $B$. T4 treatment significantly increased both NGF and EGF concentrations compared to control values (B versus $\mathrm{A}, p<$ 0.01 ). $\mathrm{T} 4$ + 6-OHDA treatment, but not 6-OHDA injection, increased glandular growth factor concentrations relative to control levels (D versus $\mathrm{A}, p<0.01$; C versus $\mathrm{A}, p<0.05$ ). Mean SMG-NGF and EGF contents were significantly lower in animals treated with $\mathrm{T} 4+6-\mathrm{OHDA}$ compared to animals treated with T4 alone ( $\mathrm{D}$ versus $\mathrm{B}, p<0.01)$.

\section{DISCUSSION}

The present study was restricted to one developmental period, i.e. 7-15 days of age. Previous studies in this laboratory have indicated that both SMG-NGF and EGF acquire T4 responsiveness during the 2 nd wk of life $(17,18)$. Early actions of T4 on SMG include cytodifferentiation and organization (30). However, thyroid hormones exert several other effects in neonatal rodents, including organization and maturation of the nervous and endocrine systems $(19,31,32)$. It is not clear whether the T4-induced increases in SMG-NGF and EGF levels are due to local SMG actions (activation of genes responsible for morphological and biochemical differentiation) or to accelerated development of the autonomic and endocrine systems. Studies with isoproterenol, a sympathomimetic amine, have shown that the SNS exerts a profound influence on the morphological and biochemical maturation of SMG in suckling rats $(33-35)$. The structural damage observed in SMG tissue as a consequence of anti-NGF treatment in preweaning animals provides further evidence for a critical trophic influence of the developing SNS on SMG tissue (36).

To assess a role for the SNS of the T4-mediated SMG-NGF and EGF responses, we used four groups of animals that were treated with T4, 6-OHDA, T4 + 6-OHDA or appropriate vehicle solutions. Pups treated with 6-OHDA (group C) and T4 + 6-

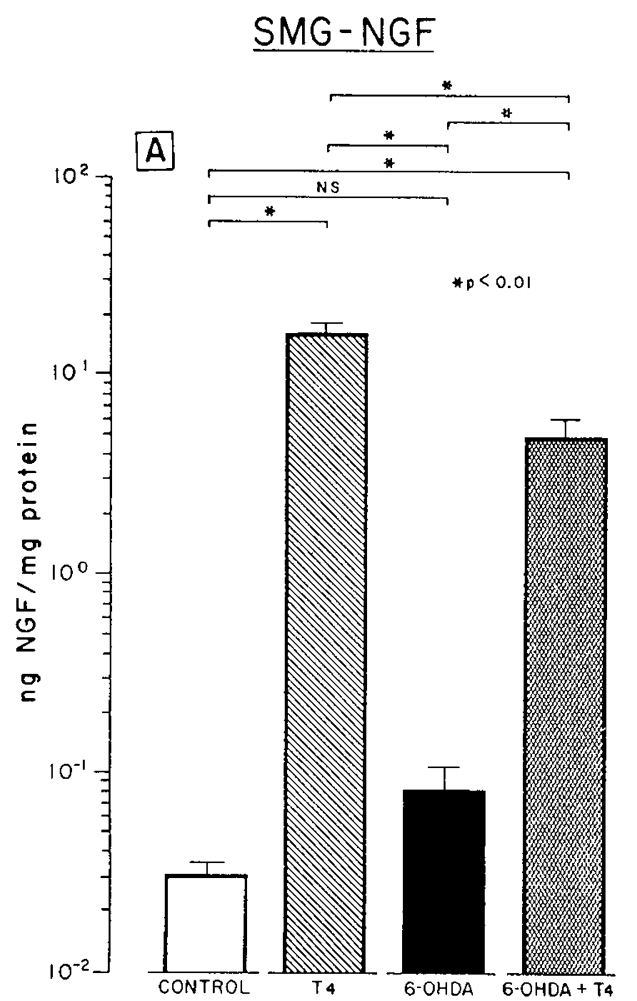

OHDA (group D) showed marked reduction in growth, as indicated by their decreased body weight and nose to rump length measurements. T4 treatment alone had no effect on growth, but did advance the time of tooth eruption and eyelid opening by one full day compared to the control animals. Tooth eruption occurred in more than $75 \%$ of control animals (group A) on day 11 , while this process was observed on day 10 in $80 \%$ of animals in T4-treated pups (group B). This finding is in close agreement with Lerman and Koldovsky (37) who reported accelerated rate of growth of teeth following T4 administration in rats during the second week of life. Eyelid opening occurred in $75 \%$ of control animals on day 14 , whereas this process was completed in $82 \%$ of animals on day 13 in T4 treated pups (group B). 6-OHDA treatment given with T4 (group D) did not prevent the accelerated teeth eruption and eyelid opening. These results indicate that the T4 effects on epidermal maturation are not critically influenced by the developing SNS during the second week of life. Animals treated with T4 + 6-OHDA (group D), however, exhibited dry and rough skin. These animals also had less hair than the other groups (A, B, and $\mathrm{C}$ ), indicating some abnormality in cutaneous development.

T4 treatment (groups B and D) raised mean serum T4 and T3 levels indicating a hyperthyroid state in these animals. However, pups treated with T4 + 6-OHDA had higher mean levels of serum T3 than the groups of pups treated with T4 alone (group $\mathrm{D}$ versus $\mathrm{B}, p<0.05$ ). It is not clear whether the serum T3 increase in group $\mathrm{D}$ is due to alteration in the $\mathrm{T} 4$ to $\mathrm{T} 3$ conversion rate or is due to other alterations in T3 metabolism (tissue uptake or release). The lack of increase in mean serum T3 levels in 6OHDA treated animals (group $C$ ) indicate that the drug treatment per se caused no alterations in the basal conversion of $\mathrm{T} 4$ to T3 or in T3 metabolism. Further work is necessary to determine the mechanism(s) by which 6-OHDA treatment influences the metabolism of exogenously administered T4 during the 2 nd wk of life.

SMG relative weights were significantly greater in all three treated groups $(\mathrm{B}, \mathrm{C}$, and $\mathrm{D})$ than in control animals (group $\mathrm{A}$ ). The data on SMG-NE measurements confirmed that the dose

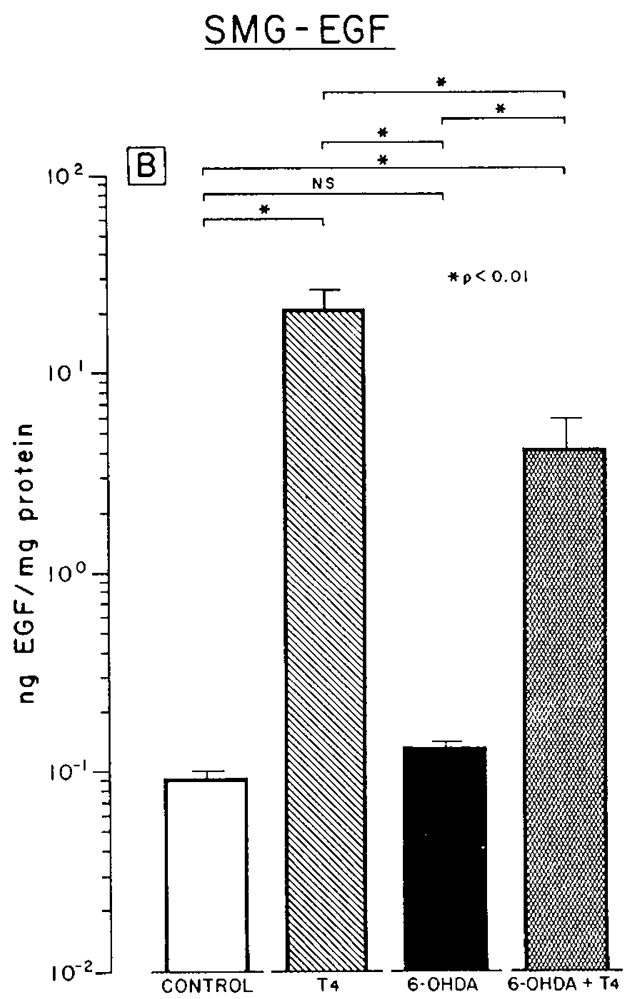

Fig. 2. Effect of neonatal T4 and/or 6-OHDA treatment on SMG-NGF $(A)$ and EGF $(B)$ levels. Littermate pups were treated with vehicle or T4 and 6-OHDA as described in Table 1. They were sacrificed on day 16. NGF and EGF measurements were made in SMG tissues removed from animals sacrificed in the experiments described in Table 1. 
and duration of 6-OHDA treatment were sufficient to cause a total destruction of sympathetic nerve terminals in SMG tissue. These results are in accordance with known effects of 6-OHDA treatment on sympathetic nerve terminals in this gland (38). In addition, the observed reduction in SCG wet weight and protein content in groups $\mathrm{C}$ and D indicate that 6-OHDA treatment impaired SNS development. Interestingly, T4 treatment alone caused a moderate reduction in wet weight and protein content of SCG compared to control animals (group $\mathrm{B}$ versus $\mathrm{A}, p<$ $0.05)$. These results indicate that the developing SNS may be sensitive to T4 as is the brain (39). Abnormalities ranging from defects in cell acquisition to inadequate development of dendritic spines have been reported in distinct brain regions of neonatal rodents treated with excess thyroid hormones early in life. In the present study the fact that T4 treatment alone (group B) did not decrease NE content in SMG tissue indicates that the action of T4 on the SCG size and protein content may be independent of its influence on sympathetic nerve terminals. Since SCG tissue represents a heterogenous population of cells, further work is necessary to delineate the nature of the cells and the individual constituents that may have been affected resulting in the reduction in ganglion size and protein content. The increases observed in mean SMG-NE content in T4 treated animals (NE, pg/gland $75150 \pm 2420$ in T4-treated group versus $46066 \pm 4540$ in vehicle treated group $p<0.05$ ) may indicate the tendency of T4 treatment to cause accelerated maturation of sympathetic nerve terminals.

T4 treatment increased both SMG-NGF and EGF levels relative to control animals. These results are in agreement with our previous findings $(17,18)$. In addition, in the present studies we observed that 6-OHDA treatment alone did not affect the mean SMG-NGF and EGF levels. However, both growth factor levels were significantly lower in T4 +6-OHDA treated pups compared to animals treated with $\mathrm{T} 4$ alone. These results indicated a requirement of sympathetic nerve terminals for maximal SMGNGF and EGF responses to T4. The specific mechanism(s) by which sympathetic nerve terminals influence SMG-NGF and EGF responsiveness to T4 is not clear. Preliminary results show significant reduction in glandular DNA content in animals treated with 6-OHDA or T4 + 6-OHDA (total DNA $\mu \mathrm{g} /$ pair SMG in groups A, B, C, and D were $35 \pm 3 ; 51 \pm 3 ; 28 \pm 3$ and $27 \pm 3$, respectively). Thus, 6 -OHDA treatment may have caused an impairment in cell acquisition. The identification of morphological (maturation of acini) and biochemical (appearance of several secretory proteins and increase in DNA synthesis) actions of isoproterenol on neonatal SMG early in life lends further support for a significant SNS role in the normal and differentiated functions of SMG tissue (33-35). Whether other neuroeffector systems (parasympathetic and sensory nervous system) play a role in T4-mediated actions remains an interesting aspect for further study.

\section{REFERENCES}

1. Cohen S 1960 Purification of a nerve growth promoting protein from the mouse salivary gland and its neurotoxic antiserum. Proc Natl Acad Sci USA 46:302-311

2. Cohen S 1962 Isolation of a mouse submaxillary gland protein accelerating incisor eruption and eyelid opening in newborn animals. J Biol Chem 237:1555-1562

3. Levi-Montalcini R, Angeletti PU 1968 Nerve growth factor. Physiol Rev 48:534-569

4. Carpenter G 1981 Epidermal growth factor. In: Baserga R (ed) Tissue Growth Factors. Springerverlag, Berlin, pp 89-132

5. Schwab ME, Stockel, K, Thoenen H 1976 Immunocytochemical localization of nerve growth factor (NGF) in the submandibular gland of adult mice by light and electron microscopy. Cell Tissue Res 169:289-299

6. Van Noorden S, Heitz P, Gregory H, Polak JM, Pearse AGE 1977 Immunostaining of mouse epithelial-epidermal growth factor: improved light and electron microscopical localization. Gastroenterology 72:826

7. Walker P, Weichsel ME, Eveleth D. Fisher D 1982 Ontogenesis of nerve growth factor and epidermal growth factor in submaxillary glands and nerve growth factor in brains of immature male mice correlation with ontogenesis of serum levels of thyroid hormones. Pediatr Res 16:520-524

8. Lacassange A 1940 Dimorphisme sexual de la glande sousmaxillamie ches la souris. Cr Soc Biol 133:180-181

9. Levi-Montalcini R, Angeletti PU 1964 Hormonal control of the NGF in the submaxillary glands of mice. In: Sreenby LM, Mayer J (eds) Salivary Glands and their Secretion. Pergaman Press, New York, pp-129-141

10. Byyny RL, Orth DN, Cohen S, Doyne ES 1974 Epidermal growth factor effects of androgens and androgenic agents. Endocrinology 95:776-782

11. Pinkstaff CA 1980 The cytology of salivary glands. Int Rev Cytol 63:142-262

12. Chretein N 1977 Action of testosterone on the differentiation and secretory activity of a target organ. The submaxillary gland of the mouse. Int Rev Cytol 50:333-396

13. Walker P, Weichsel ME, Hoath SB, Poland RE, Fisher DA 1981 Effect of thyroxine, testoserone and corticosterone on nerve growth factor (NGF) and epidermal growth factor (EGF) concentrations in adult female mouse submaxillary gland. Dissociation of NGF and EGF responses. Endocrinology 109:582-587

14. Ishii DN, Shooter EM 1975 Regulation of nerve growth factor synthesis in mouse submaxillary glands by testosterone. J Neurochem 25:943-951

15. Snell R 1960 The effect of preganglionic parasympathectomy on the structure of the submandibular and major sublingual glands of the rat. Z Zelljorsch Microsk 52:686-696

16. Wells H, Handleman C, Milgram E 1961 Regulation by sympathetic nervous system of accelerated growth of salivary glands of rats. Am J Physiol 201:707710

17. Lakshmanan J, Beri U, Perheentupa J, Grueters A, Kim H, Macaso T, Fisher DA 1984 Acquisition of submandibular gland nerve growth factor (SMG$\mathrm{NGF}$ ) responsiveness to thyroxine administration in neonatal mice. $\mathbf{J} \mathrm{Neu}-$ rosci Res 12:71-81

18. Lakshmanan J, Perheentupa J, Grueters A, Hoath SB, Masco T, Fisher DA 1983 Critical times for EGF-thyroxine interactions in neonatal mice. Endocrinology 113 (suppl): T-20

19. Ford DH, Cramer EB 1977 Developing nervous system in relation to thyroid hormones. In: Grave GD (ed) Thyroid Hormones and Brain Development. Raven Press, New York, pp 1-18

20. Gresik EW 1976 Preliminary observations on the effects of chronic hypothyroidism on the development of the superior cervical ganglion of the rat Brain Res 110:619-622

21. Peuler JD, Johnson GA 1977 Simultaneous single isotopic assay of plasma norepinephrine, epinephrine and dopamine. Life Sci 21:625-636

22. Mobley WC, Schenker A, Shooter EM 1976 Characterization and isolation of proteolytically modified nerve growth factor. Biochemistry 15:5543-5552

23. Chapman CA, Banks BE, Carstairs JR, Pearce FL, Vernon CA 1979 The preparation of nerve growth factor from the prostate of the guinea pig and isolation of immunogenically pure material from the mouse submandibular gland. FEBS Lett 105:341-344

24. Greenwood FC, Hunter WM, Glover JS 1962 The preparation of ${ }^{131}$ I-labelled human growth hormone of high specific radioactivity. Biochem J 89:114124

25. Walker P, Weichsel ME, Guo SM, Fisher DA 1980 Radioimmunoassay for mouse nerve growth factor (NGF). Effects of thyroxine administration on tissue NGF levels. Brain Res 186:331-341

26. Savage CR, Cohen S 1972 Epidermal growth factor and a new derivative Rapid isolation procedures and biological and chemical characterization. J Biol Chem 247:7609-7611

27. Hoath SB, Lakshmanan J, Scott SM, Fisher DA 1983 Effect of thyroid hormones on epidermal growth factor concentration in neonatal mouse skin. Endocrinology 1 12:308-314

28. Chopra IJ 1972 A rapid radioimmunoassay for measurement of thyroxine in unextracted serum. J Clin Endocrinol Metab 34:938-946

29 Chopra IJ, Ho RS, Lam RW 1972 An improved radioimmunoassay of triidothyronine in serum. Its application to clinical and physiological studies. J Lab Clin Metab 80:729-739

30. Aloe L, Levi-Montalcini R 1980 Comparative studies on testosterone and L-thyroxine effects on the synthesis of nerve growth factor in mouse submaxillary glands. Exp Cell Res 125:15-22

31 Bakke JL, Geillert RJ, Lawrence NL 1970 The persistent effects of perinatal hypothyroidism on pituitary, thyroidal and gonadal functions. J Lab Clin Med 76:25-33

32. Coulombe P, Ruel P, Dussault H 1980 Effect of neonatal hypo and hyperthyroidism on pituitary growth hormone content in the rat. Endocrinology 107:2027-2033

33. Schneyer CA, Shackleford JM 1963 Accelerated development of salivary glands of early postnatal rats following isoproterenol. Proc Soc Exp Biol Med 112:320-324

34. Chang WWL, Barka T 1972: Stimulation of DNA synthesis by isoprotereno in rat submandibular gland during postnatal growth. J Cell Biol 55:38a(abstr)

35. Ekfors T, Chang WWL, Bressler RS, Barka T 1972 Isoproterenol accelerates the postnatal differentiation of rat submandibular gland. Dev Biol 29:38-47

36. Caramia F Angeletti PU, Levi-Montalcini R 1962 Experimental analysis of the mouse submaxillary gland in relationship to its nerve growth factor content. Endocrinology 70:915-922

37. Lerman R, Koldovsky O 1979 Growth and food intake of prematurely weaned rats: effects of cortisone and thyroxine injection during the suckling period. J Nutr 109:916-923

38. Yodlowski ML, Fredieu JR, Landis SC 1984 Neonatal 6-hydroxydopamine treatment eliminates cholinergic sympathetic innervation and induces sensory sprouting in rat sweat glands. J Neurosci 4:1535-1548

39. Morreale de Escobar G, Escobar del Rey F 1980 Brain damage and thyroid hormone. In: Burrow GN, Dussault JH (eds) Neonatal Thyroid Screening. Raven Press, New York, pp 25-50

40. Peterson GIL 1977 A simplification of the protein method of Lowry et al which is more generally applicable. Anal Biochem 83:346-356 